\title{
LA UNIVERSIDAD DE BARCELONA EN EL NO-DO (1943-1975): ANÁLISIS DE LA EDUCACIÓN SUPERIOR A TRAVÉS DE LA VERDAD OFICIAL DEL REGIMEN FRANQUISTA*
}

\author{
Jordi Garcia Farrero** \\ Anna Gómez-Mundó***
}

\section{RESUMEN}

Este artículo estudia la representación de la Universidad de Barcelona en uno de los instrumentos de propaganda más importantes de la dictadura franquista: el NO-DO (Noticiarios y Documentales Cinematográficos). Para ello, se han recopilado y analizado todas las noticias relativas a la institución universitaria aparecidas en él, llegando a identificar tres claves interpretativas del sentido de la verdad oficial: la lucha por el poder, la exaltación de la jerarquía y la vida académica.

Palabras clave: universidad, franquismo, NO-DO, propaganda.

\footnotetext{
* La investigación que ha dado lugar a estos resultados se ha desarrollado en el marco de la investigación financiada por el Programa Estatal de Investigación, Desarrollo e Innovación Orientada a los Retos de la Sociedad, en el marco del Plan Estatal de Investigación Científica y Técnica y de innovación 2013-2016. Proyecto: ARAEF. Análisis de las representaciones audiovisuales de la educación en documentales y noticiarios durante el franquismo. Ref. EDU2017-89646-R.

${ }^{* *}$ Universitat de Barcelona (UB), Barcelona, Espanha.

${ }^{* * *}$ Universitat de Vic - Universitat Central de Catalunya (Uvic), Barcelona, Espanha.
} 


\title{
A UNIVERSIDADE DE BARCELONA NO NO-DO (1943- 1975). ANÁLISE DA EDUCAÇÃO SUPERIOR POR MEIO DA VERDADE OFICIAL DO REGIME FRANQUISTA
}

\section{RESUMO}

Este artigo estuda a representação da Universidade de Barcelona em um dos instrumentos de propaganda mais importantes da ditadura franquista: o NO-DO (Noticiários e Documentários Cinematográficos). Para isso, foram analisadas todas as notícias referentes a esta instituição universitária, chegando a identificar três chaves interpretativas do sentido da verdade oficial: a luta pelo poder, a exaltação da hierarquia e a vida acadêmica.

Palavras-chave: universidade, franquismo, NO-DO, propaganda.

\section{THE REPRESENTATION OF THE UNIVERSIDAD DE BARCELONA IN NO-DO (1943-1975). ANALYSIS OF HIGHER EDUCATION AS DEPICTED IN THE OFFICIAL TRUTH OF THE FRANCO REGIME}

\begin{abstract}
This paper studies the representation of the Universidad de Barcelona in one of the most important propaganda instruments of the Franco dictatorship: NO-DO (cinematographic news and documentaries). We have collected and analyzed all references to the university and identified three interpretative dimensions of the official truth: the fight for power, the exaltation of hierarchy and academic life.
\end{abstract}

Keywords: university, francoism, NO-DO, propaganda.

\section{LA UNIVERSIDAD DE BARCELONA DANS LE NO-DO (1943-1975). ANALYSE DE L'ENSEIGNEMENT SUPERIEUR A TRAVERS DE LA VERITE OFFICIELLE DU REGIME FRANQUISTE}

\section{RÉSUMÉ}

Cet article étudie la représentation du la Universidad de Barcelona dans l'un des plus importants instruments de la propagande de la dictature franquiste: le NO-DO (nouvelles et documentaires cinématographiques). Toutes les nouvelles relatives à l'institution universitaire sont collectées, en identifient trois clés pour l'interprétation du sentit de la vérité officielle: le combat pour le pouvoir, l'exaltation de la hiérarchie et la vie académique.

Mots-clés: université, franchisme, NO-DO, propagande. 


\section{INTRODUCCIÓN}

No hay duda de que en las instituciones universitarias es donde más se evidenció la relación problemática que mantuvo el régimen franquista (19391975) con el mundo de la cultura y de la ciencia. La incomodidad que suponían las universidades en el encaje del sistema dictatorial se incrementó a medida que transcurrían los años, llegando a agravarse significativamente a partir de la década de los sesenta. Según señala Borja de Riquer (2010), parece ser que Franco nunca se olvidó de que la dictadura de Primo de Rivera se vio notablemente deteriorada a causa de las protestas que se organizaron desde la universidad por la aprobación del Decreto ley de 19 de mayo de 1928 y, además, en todo momento tuvo muy presente que la mayor parte de la comunidad académica se manifestó a favor de la causa republicana. Conocer el recuerdo ingrato que para el Caudillo suponía la actividad universitaria en el pasado hace más fácil comprender el ahínco en los objetivos que se plantearon en los primeros años de la dictadura, como el de "reconstruir la Universidad en el orden del espíritu afincándola sobre un recio sentido católico e inyectando en sus venas el fervor de exaltación patriótica de nuestro Movimiento" (IBÁÑEZ MARTÍN, 1944, p. 6). El propósito se llevó a cabo por medio de varias iniciativas legislativas, como lo fue la aprobación de una nueva ley de ordenación de la universidad española (1943) de espíritu nacionalsindicalista y, por supuesto, del establecimiento de un sistema represivo en todas sus modalidades posibles (exilio, encarcelamiento, depuración, expulsión, oposiciones patrióticas) que destruyó la mayoría de los claustros académicos españoles.

Es evidente que la Universidad de Barcelona no quedó al margen de esta nueva configuración universitaria que quería imponer más bien una contrarrevolución pedagógica (LÓPEZ BAUSELA, 2011), es decir, un retorno a la tradición hispánica de la Inquisición abandonando la voluntad de participar en las corrientes de pensamiento contemporáneas. Era, pues, la irrupción del modelo universitario del Nuevo Estado que conectaba con los discursos educativos acaecidos durante los primeros años del franquismo (LAUDO; 
VILANOU, 2015; VIÑAO, 2014). Aun así, también es cierto que la Universidad de Barcelona presenta una serie de particularidades dentro de un contexto español que explica que dirijamos nuestra atención a esta institución académica. El profesor Jaume Claret (2003) destaca que la propia situación geográfica de la capital catalana como retaguardia durante la Guerra Civil (1936-1939) había obligado a posicionarse políticamente a la mayor parte del claustro alrededor de los ideales republicanos y catalanistas y, por este motivo, posteriormente fue especialmente represaliada. De esta manera, se emprendió una feroz represión en la Universidad de Barcelona a través de un juez y a la vez rector, Francisco Gómez del Campillo (1873-1945), que castigó al profesorado tanto por sus realizaciones académicas como por su ideología que, en opinión del régimen, lo había impregnado absolutamente todo. Ciertamente la captura de los archivos republicanos fue determinante. En fin, la consecuencia de todo ello fue la pérdida del 71,38\% de su plantilla (GRACIA; FULLOLA, 2008) y, a nivel simbólico, la sustitución del escudo de Cataluña de la fachada principal por el antiguo escudo real, la supresión de la palabra "libertas" del escudo de la universidad y la desaparición de los retratos de profesores exiliados, como el de Jaume Serra Hunter (1878-1943) o el de Pere Bosch Gimpera (1891-1974).

Tomando en cuenta estos puntos de partida, este artículo estudia todas las noticias del NO-DO (acrónimo de Noticiarios y Documentales Cinematográficos y, a partir del año 1968, Revista Cinematográfica Española) que hacen referencia a la Universidad de Barcelona, junto con otras instituciones de educación superior que mantenía algún tipo de relación, como una expresión política y cultural que configura una narrativa con una explícita pretensión de difusión de un mensaje político. Por ser una narrativa de expresión política se han tenido presentes en todo momento los tres momentos (pseudofascista y potencialmente imperialista, nacionalcatolicismo corporativo y "desarrollismo tecnocrático" con una evolución lenta hacia el autoritarismo burocrático) que experimentó el franquismo a lo largo de su existencia (PAYNE, 2019, p. 229), aunque todos ellos tienen en común la voluntad de destruir cualquier intento modernizador o reconocimiento de Cataluña como sujeto político que recordase 
los años republicanos. Añadir que para el estudio de la cuestión se ha establecido un diálogo hermenéutico con la fuente audiovisual para averiguar cuál fue la verdad oficial del régimen académico sobre su modelo académico a propósito de la Universidad de Barcelona soñada por las autoridades franquistas. Todo ello se ha realizado a través del análisis de las cinco preguntas básicas que permiten evaluar la amplitud, la diversidad y la sensibilidad humana de la mirada informativa: “¿quién enfoca?, ¿a quién enfoca?, ¿en qué actuaciones?, ¿̇en qué escenarios? y ¿utilizando qué fuentes?” (MORENO; ROVETTO; BUITRAGO, 2007, p. 41).

Con todo, el análisis no sería suficientemente riguroso si no incorporásemos en las claves interpretativas las discontinuidades que hallamos entre quien investiga y el material investigado. En este estudio se encuentran claramente dos ejes de discontinuidad: el eje narrativo -el material estudiado es de carácter audiovisual y la narrativa de los investigadores es la escritura- y el eje generacional - el período estudiado se ubica en un tiempo en que los investigadores aún no habían nacido. Eso explica la importancia de tener cierta precaución para que la comunidad imaginada no intervenga con el sesgo interpretativo que puede provocar (GÓMEZ, 2014). Aun así, y a pesar del ejercicio de mirar de nuevo aquello que se cree conocer despojándonos de ideas preconcebidas no siempre contrastadas, también debemos estudiar con las ideas que sabemos y que son ampliamente contrastadas, como la de que las autoridades franquistas llevaron a cabo un enfoque totalmente sesgado y superficial porque el régimen siempre presentaba las noticias a favor de la perfección de la obra del Estado nuevo. Dicho de otro modo: su pretensión era más bien de desinformar que de informar (GRACIA; RUIZ CARNICER). Es, por este motivo, que también serán muy importantes los diálogos realizados con los libros de referencia en la historiografía catalana y española. En definitiva, como escribía Peter Burke (2012): "Las memorias del conflicto son también los conflictos de la memoria" (p. 86), y si tomamos buena nota de ello debemos armarnos con las aproximaciones metodológicas más honestas y rigurosas que tenemos a nuestro alcance. Así es como hemos proseguido en nuestro empeño de indagar, a través del discurso 
tanto visual como oral, el mensaje propagado por un canal oficial del Régimen tomando como protagonista de su hilo discurso la Universidad de Barcelona.

\section{EL NO-DO COMO APARATO DE PROPAGANDA DEL RÉGIMEN}

No descubriremos nada si afirmamos que el NO-DO fue, con el permiso de la radio - porque "en 1943 había en España más de un millón de aparatos de radio, el triple que en 1936. Hacia 1955 ya eran unos 3 millones, lo cual significaba que el 47 por 100 de los hogares españoles disponían de este medio de comunicación de masas" (DE RIQUER, 2010, p. 333) -, uno de los elementos más relevantes de la política comunicativa del régimen. Es bien sabido que nació en 1942 después de la experiencia del Noticiario Español (1931-1938) y la influencia de otros noticiarios internacionales que ya se habían convertido en referentes (UFA de Alemania, LUCE de Italia o FOX Movietone de Estados Unidos), aunque su primera edición no llegó hasta el año siguiente, y a pesar de múltiples acontecimientos que fueron producto básicamente del contexto político y social, perduró más allá del régimen franquista (1981) con un elevado grado de penetración social a pesar de que fue perdiendo relevancia a raíz de la aparición de Televisión Española (1956). Su propósito no permitía ninguna confusión: "con el fin de mantener, con impulso propio y directriz adecuada, la información cinematográfica nacional"1. O dicho de una forma más clara: "dar información visual sobre actos y actividades del régimen y reforzar el culto a la personalidad del dictador, la guerra y las espectaculares imágenes del conflicto para una sociedad que apenas ha asimilado la radio" (GRACIA; RUIZ, 2001, p. 85).

A grandes rasgos, debe tenerse en cuenta que el NO-DO estuvo dirigido durante los primeros años por el partido único permitido durante el franquismo,

1 Véase: Boletín Oficial del Estado, n. 356, 22/12/1942, p. 10444. Disponible en: https://www.boe.es/datos/pdfs/BOE//1942/356/A10444-10444.pdf Acceso en: nov. 2019. 
Falange Española Tradicionalista y de las Juntas de Ofensiva Nacional Sindicalista (FET y de las JONS), que dependía de la Secretaría General del Movimiento. Fueron los años en que los falangistas intentaron transmitir una ideología más determinada porque eran partidarios de las tesis nacionalsocialistas alemanas (Ramón Serrano Suñer). Sin embargo, después esto cambió porque pasó a formar parte del control de los católicos, con un posicionamiento más próximo a los aliadófilos, a través del Ministerio de Educación y, concretamente, de la Subsecretaría de Educación Popular. Los cambios no acabaron aquí porque, a raíz de la remodelación ministerial (1951), el NO-DO se convirtió, para siempre, en una de las responsabilidades de la cartera, de nueva creación, de Información y Turismo (Dirección General de Cinematografía y Teatro), que dio tanta popularidad al político Manuel Fraga (1922-2012), sin olvidarnos de Gabriel Arias-Salgado (1904-1962) durante los años anteriores. Ciertamente la incorporación del NO-DO en este nuevo ministerio supuso un cambio eminentemente de incremento de gasto presupuestario que impulsó aún más el poder y la autonomía del ente:

una importante renovación de elementos técnicos y materiales. Un fondo especial del mismo de 11.871.158 ptas., librado en el bienio 19511952, se destinará a la compra de terrenos y a la construcción de nuevas dependencias. [...] Con él, el NO-DO puede disfrutar de unas instalaciones modernas, acordes con la dimensión que había alcanzado su actividad (TRANCHE; SÁNCHEZ-BIOSCA, 2000, p. 58).

Realmente el NO-DO fue un organismo con una cierta autonomía hasta que la Jefatura del Estado decidió su plena integración a la Corporación de Radiotelevisión Española (1980) ${ }^{2}$. Buena prueba de ello fue su personalidad económica, jurídica y administrativa propia, que puede leerse en el Reglamento para la organización y funcionamiento (1942)3. Presentaba una subvención del

\footnotetext{
${ }^{2}$ Ley 4/1980, 10 de enero, Estatuto de la Radio y la Televisión (Boletín Oficial del Estado, n. 11, 12 de enero de 1980, p. 843). Disponible en: https://www.boe.es/boe/dias/1980/01/12/pdfs/Aoo844-00848.pdf Acceso en: nov. 2019.

3 Consultado en: TRANCHE, Rafael R.; SÁNCHEZ-BIOSCA, Vicente. NO-DO: el tiempo y la
} 
Estado y los ingresos producidos directamente por la explotación del NO-DO. Debe recordarse que este noticiero era obligatorio en todas las salas de cine y, al mismo tiempo, estos establecimientos tenían que pagar un alquiler de la cinta por su reproducción. Ahora bien, tampoco puede interpretarse que este noticiario tuviera una trayectoria independiente a la del régimen porque es evidente que estuvo influenciado por las necesidades del franquismo. No nos puede extrañar, pues, que "se depuró el oficio periodístico y la censura se alzó como el principal elemento del mensaje: no sólo eliminó las opiniones disidentes, sino que construyó un discurso favorable al Régimen para su aceptación social" (RODRÍGUEZ MATEOS, 2008, p. 14).

\section{LA PRESENCIA DE LA UNIVERSIDAD DE BARCELONA EN EL NOTICIARIO}

Sorprende, en primer lugar, la poca atención comunicativa que recibieron las universidades y la educación superior en general por parte del régimen. Menos aún lo hizo con la Universidad de Barcelona a pesar que el NODO tenía una corresponsalía en la capital catalana. Basta comparar los registros que ocupó dicha institución (25, un 11\%) frente a los contabilizados relativos a la Universidad de Madrid (124, un 42\%)4. La desproporción puede comprenderse parcialmente si recordamos que la Universidad de Madrid junto con el Consejo Superior de Investigaciones Científicas (CSIC) representaban una simbiosis como cúspide del poder académico (CANALES, 2009), un poder que ya venía heredado de la reforma liberal de 1845 a raíz de la distribución de las universidades en un sistema radial. Esto tampoco nos debe ocultar que la Universidad de Barcelona representó uno de los escenarios más importantes de la conquista cultural de

memoria. Madrid: Filmoteca española, 2000. p. 585-587.

4 En este sentido, se puede consultar tota esta información en el siguiente documento: Registro de los reportajes y noticias en los que aparece representada la Educación (1940-1975). Disponible en: https://www.uvic.cat/museu-virtual/investigacions/araef Acceso en: abril 2020. 
Cataluña (AGUILAR, 2006) porque, al ser considerada sin ningún tipo de matices uno de los principales enemigos de la llamada "universidad imperial", se quiso erradicar todo vestigio que tuviera alguna relación con la experiencia de autonomía universitaria que disfrutó durante el gobierno republicano y, además, había quedada asociada totalmente al catalanismo político.

Más tarde, sin embargo, el régimen se apropió, en un ambiente de desarrollismo tecnocrático, del nombre de aquel modelo universitario creando la Universidad Autónoma de Barcelona (1968) para borrar el recuerdo republicano y, además, estableció una estrategia para reducir el impacto de las protestas tal y como ya había hecho el régimen militar brasileño con la creación de la Cidade Universitária Armando de Salles Oliveira en la ciudad de São Paulo (CLARET, 2017). Aun así, la iniciativa no tuvo mucho éxito, como evidencian las siguientes palabras:

\begin{abstract}
Los primeros tiempos de la UAB fueron difíciles. Más allá de las dificultades propias de emprender un proyecto como aquel, se tuvo que trabajar contra los recelos de la antigua y hasta entonces única universidad de Barcelona. En sectores en que se conservaba vivo el prestigioso recuerdo de la Universidad Autónoma republicana, el nombre de la nueva institución creó confusión, sino un rechazo directo. [...] La idea de autonomía universitaria se basaba en cuatro ejes: libre administración de los recursos, libre contratación de personal docente, libre admisión de los alumnos y libre organización de planes docentes (POBLET; DURAN, 2006, p. 196-197).
\end{abstract}

Llegados a este punto, he aquí las noticias a partir de las cuales el NO-DO produjo su particular visión de la Universidad de Barcelona y, a partir de ellas, estableceremos las tres claves interpretativas que posteriormente merecerán nuestra atención (Cuadro 1): 
Cuadro 1 - Relación de noticias del NO-DO sobre el Distrito de la Universidad de Barcelona (1943-1975).

\begin{tabular}{|c|c|c|}
\hline AÑO & NÚMERO NO-DO & TITULAR DE LA NOTICIA \\
\hline 1947 & $231 \mathrm{~A}$ & $\begin{array}{l}\text { Franco en Barcelona. La universidad y el Frente de } \\
\text { juventudes rinden homenaje al Jefe de Estado. }\end{array}$ \\
\hline 1947 & $238 \mathrm{~A}$ & $\begin{array}{l}\text { Confraternidad hispano-marroquí. Un grupo de } \\
\text { estudiantes musulmanes de la Escuela Politécnica de } \\
\text { Tetuán visita Barcelona en viaje de estudios. }\end{array}$ \\
\hline 1948 & $302 \mathrm{~A}$ & El Congreso Internacional de Filosofía en Barcelona. \\
\hline 1949 & $338 \mathrm{~B}$ & $\begin{array}{l}\text { Viajes del Generalísimo en los centros de la Universidad } \\
\text { industrial de Barcelona. Ofrenda de los aprendices. }\end{array}$ \\
\hline 1952 & $511 \mathrm{~A}$ & $\begin{array}{l}\text { En el Paraninfo de la Universidad. El ministro de } \\
\text { Educación nacional, Joaquín Ruiz-Giménez, inaugura el } \\
\text { curso académico. }\end{array}$ \\
\hline 1952 & $514 \mathrm{~B}$ & $\begin{array}{l}\text { Se celebra el octavo Congreso nacional de Pediatría. En } \\
\text { la Facultad de Medicina. La Lucha contra la mortalidad } \\
\text { infantil. }\end{array}$ \\
\hline 1955 & $630 \mathrm{~A}$ & $\begin{array}{l}\text { Humor estudiantil. La fiesta de San Raimundo de } \\
\text { Peñafort en Barcelona. Los estudiantes de Derecho del } \\
\text { SEU se divierten. }\end{array}$ \\
\hline 1955 & $636 \mathrm{~B}$ & $\begin{array}{l}\text { Panorama de curiosidades. Los estudiantes de Barcelona } \\
\text { celebran la fiesta de Santo Tomás. Cabalgata } \\
\text { humorística. }\end{array}$ \\
\hline 1956 & $689 B$ & $\begin{array}{l}\text { Humor estudiantil. Con motivo de la fiesta de Santo } \\
\text { Tomás. Alegre cabalgata en Barcelona. }\end{array}$ \\
\hline 1956 & $703 \mathrm{~B}$ & $\begin{array}{l}\text { Enseñanza y construcciones. Las obras de la ciudad } \\
\text { universitaria de Barcelona. }\end{array}$ \\
\hline 1957 & $774 \mathrm{~A}$ & $\begin{array}{l}\text { El Generalísimo en la ciudad residencial de educación y } \\
\text { descanso. Recorrido por la Universidad Laboral. }\end{array}$ \\
\hline 1958 & $787 \mathrm{~A}$ & $\begin{array}{l}\text { Humor estudiantil. Alegría de los universitarios } \\
\text { barceloneses. Juicio bufo y cabalgata. }\end{array}$ \\
\hline 1958 & $811 \mathrm{~B}$ & $\begin{array}{l}\text { Torneo de inventores. La escuela de ingenieros } \\
\text { industriales de Barcelona. Aparatos ingeniosos. }\end{array}$ \\
\hline
\end{tabular}




\begin{tabular}{|c|c|c|}
\hline AÑ̃ & NÚMERO NO-DO & TITULAR DE LA NOTICIA \\
\hline 1958 & 818B & $\begin{array}{l}\text { Congreso internacional psiquiatras y psicoterapeutas en } \\
\text { Barcelona. Inauguración en la universidad. }\end{array}$ \\
\hline 1958 & $827 \mathrm{~B}$ & $\begin{array}{l}\text { Nuevas aulas. En la ciudad universitaria de Barcelona. } \\
\text { La flamante facultad de Derecho. }\end{array}$ \\
\hline 1961 & $987 \mathrm{C}$ & $\begin{array}{l}\text { Inauguraciones en Barcelona. La Escuela de Altos } \\
\text { Estudios Mercantiles. }\end{array}$ \\
\hline 1963 & 1089B & $\begin{array}{l}\text { El barco-universidad "Seven seas" en Barcelona. Lleva a } \\
\text { bordo } 250 \text { estudiantes norteamericanos. }\end{array}$ \\
\hline 1964 & $1126 \mathrm{~A}$ & $\begin{array}{l}\text { Campamento original en Ampurias. Estudiantes de } \\
\text { Arqueología realizan excavaciones. }\end{array}$ \\
\hline 1965 & $1173 \mathrm{~A}$ & El Instituto de investigaciones pesqueras de Barcelona. \\
\hline 1967 & $1263 \mathrm{~B}$ & $\begin{array}{l}\text { Mejoras en las instalaciones universitarias de Barcelona. } \\
\text { Nuevos comedores de autoservicio. }\end{array}$ \\
\hline 1967 & $1301 B$ & $\begin{array}{l}\text { Nuevo centro docente barcelonés. Escuela Superior de } \\
\text { Bellas Artes de San Jorge. }\end{array}$ \\
\hline 1969 & $1373 \mathrm{~A}$ & $\begin{array}{l}\text { Nueva facultad de Ciencias Políticas, Económicas y } \\
\text { Comerciales. }\end{array}$ \\
\hline 1969 & $1404 \mathrm{~A}$ & $\begin{array}{l}\text { Nuevo edificio e instalaciones de la Escuela Superior de } \\
\text { Bellas Artes de San Jorge. Aulas de dibujo y pintura. }\end{array}$ \\
\hline 1971 & $1486 \mathrm{~A}$ & $\begin{array}{l}\text { V Congreso Nacional de Bioquímica en Barcelona. } \\
\text { Declaraciones de los profesores Severo Ochoa y Juan } \\
\text { Oro. }\end{array}$ \\
\hline 1975 & $1673 \mathrm{~A}$ & $\begin{array}{l}\text { Cincuenta años del "Metro" en Barcelona. Alumnos de la } \\
\text { Escuela de Bellas Artes decoran la estación de Santa } \\
\text { Cristina. }\end{array}$ \\
\hline
\end{tabular}

Fuente: Elaboración propia.

\section{SOBRE LA REPRESENTACIÓN DE LAS NOTICIAS ACADÉMICAS}

Pues, bien, a nadie se le escapa que el NO-DO como "película 
cinematográfica en la que se ilustran noticias de actualidad" (ZUBIAUR CARREÑO, 2005, p. 212) consiguió convertirse en un instrumento de educación popular muy potente que contribuyó, a pesar de los cambios políticos que se produjeron, a la supervivencia de la dictadura tal y como nos demuestra la propia historia. Y, a partir de esta premisa, ahora queremos destacar cuáles fueron los ejes narrativos más recurrentes que consideramos tras pensar la Universidad de Barcelona a través de las imágenes de la propaganda política franquista sobre, es decir, la lucha por el poder de la universidad, la exaltación de la jerarquía y, en menor escala respeto a los anteriores, la vida académica. Es importante añadir que el primer elemento es totalmente implícito, a diferencia de los otros dos y, además, que el contenido de todas las noticias seleccionadas ha sido analizado siguiendo el plan de trabajo propuesto por la profesora Rodríguez Mateos (2008), es decir, procedencia del metraje, duración y orden de la noticia, acontecimiento referido, tratamiento del hecho, protagonistas, análisis técnico, comentario en off, música y objetivo de la noticia.

Está claro que el estudio del NO-DO supone una oportunidad para conocer cómo fue representada una de las universidades más importantes durante del franquismo por varios motivos políticos ya comentados anteriormente que, al mismo tiempo, "permite aproximarse con preguntas que abran sus vínculos con la verdad, esto es, sobre su forma de dar testimonio de una existencia, y que no clausuran sus sentidos limitándose a denunciar sus mentiras" (DUSSEL, 2018, p. 26-27).

\section{LUCHA POR EL PODER DE LA UNIVERSIDAD}

Además de la voluntad de asegurarse el control militar de todo el Estado, una de las tareas principales del régimen después de la Guerra Civil fue la de intentar retomar la vida en las condiciones más normales posibles. No fue una empresa nada fácil porque los efectos del conflicto bélico estaban muy presentes en todas partes, unos efectos que recordaban el pasado reciente y que coincidían 
en el tiempo con la lucha entre diferentes sectores del régimen con la intención de conquistar diferentes parcelas de poder.

La universidad fue una de ellas y, según el profesor Borja de Riquer (2010), fue la única institución educativa que permaneció fuera del control directo de la Iglesia. Ésta solo pudo obtener la Dirección de Formación Religiosa Universitaria, que posibilitó, a través de la aprobación de la Ley de Ordenación Universitaria (LOU) de 1943, la introducción de una asignatura obligatoria en todos los estudios universitarios. De este modo, se puede afirmar que el panorama universitario presentaba la siguiente situación justo al inicio del franquismo:

\footnotetext{
Para la Iglesia se trataba de recuperar el área de influencia y control arrebatada por el descreimiento liberal de la República y, para Falange, su más firme compromiso con el régimen pasaba por asegurar la perpetuación de una ideología capaz de impulsar la realidad de una revolución, por el momento, estancada (GRACIA, 1996, p. 40-41).
}

Esta lucha entre los nacionalcatólicos y los falangistas puede advertirse en las imágenes del NO-DO estudiadas. Siempre, como es lógico, sin olvidarnos del cariz de este noticiero, que anteriormente hemos puesto de manifiesto. Ahora bien, se puede destacar que en los primeros compases de este medio de masas (NO-DO números 231A y 774A) se pueden observar grupos de estudiantes que saludan con el brazo levantado en una universidad que celebraba masivamente el Día del Estudiante Caído como homenaje a Matías Montero (9 de febrero) y, especialmente, la festividad de Santo Tomás de Aquino (7 de marzo), que convocaba a los estudiantes a una serie de celebraciones. No hay duda de que durante aquellos años - conocidos como la "etapa azul" - predominaba un discurso cultural falangista, es decir, un discurso de exaltación nacionalista, de vindicación del papel salvador del ejército y de culto al Caudillo.

En este sentido, se puede afirmar que, según Gracia y Ruiz (2001), existieron dos tipos de falangismos en el contexto académico durante aquellos 
años. Por un lado, destacamos aquel sector que podemos denominar la "Falange auténtica" y es el que realmente aparece en el NO-DO. Realizaban acciones directas y violentas a favor de Franco, los caídos y, por supuesto, de los totalitarismos italiano y alemán. También se vivieron constantes episodios de represión contra estudiantes que hablaran en catalán o con familiares políticamente sospechosos. No hay duda de que el Sindicato Español Universitario (SEU) fue uno de los agentes más activos, a pesar de que nunca tuvo un gran arraigo. He aquí dos ejemplos: pasó, entre 1939 y 1942, de 4.700 a 2.250 afiliados, y, por otro lado, tan solo consiguió movilizar un centenar de estudiantes hacia la División Azul. En cualquier caso:

entre 1933 y 1965 transcurren los poco más de treinta años de vida de un Sindicato Español Universitario tempranamente fracasado en sus objetivos esenciales, políticamente maltratado por compañeros de filas y perpetuado históricamente por cuanto suscitaron sus propios y preceptivos afiliados desde la crítica o la disidencia interior. Cuando en 1965 se promulgan los decretos para la nueva organización de los estudiantes en las Agrupaciones Profesionales de Estudiantes, el SEU es un cadáver político unánimemente repudiado (GRACIA, 1996, p. 39).

Por otro lado, existe la "Falange excepcional", formada por una serie de intelectuales: Pedro Laín Entralgo, Antonio Tovar o Dionisio Ridruejo. Promovieron, siempre con fidelidad a la dictadura (concepto unidad de la patria española) a pesar de un posicionamiento más bien crítico, una reflexión más profunda y plural (revistas Alférez, Escorial o Cuadernos para el Diálogo) y, en algunos momentos, ciertos planteamientos educativos que invitaban a una cierta apertura dentro de los márgenes que marcaba el régimen, tal y como sucedió durante la etapa de Joaquín Ruiz-Giménez al frente del ministerio (1951-1956) que en el NO-DO número 511A podemos verlo como inauguraba el curso académico en la universidad catalana. Esta voluntad política de establecer un régimen más homologable internacionalmente no tuvo, sin embargo, mucho recorrido porque es bien conocido que este catedrático español dejó de formar parte del núcleo de autoridades franquistas posteriormente y hasta incluso acabó 
renunciando a su puesto de procurador en las Cortes franquistas, tras los incidentes de 1965 en la Universidad de Madrid (RUIZ-GIMÉNEZ, 2013).

Además, la situación política cambió totalmente después de la Segunda Guerra Mundial (1939-1945), hecho que benefició al nacionalcatolicismo. La nueva coyuntura internacional lo proyectó a convertirse en el eje central de los planteamientos y prácticas políticas del régimen en materia universitaria. Dicho de otro modo:

Las diferentes fases de la Segunda Guerra Mundial influyeron decididamente en la dinámica política española, que fluctuó entre la reafirmación de la dictadura y de su orientación fascista hasta ponerla en crisis y favorecer un maquillaje que forzaba un declive de la estética en favor de la presencia más importante del argumentario católico (SANTACANA, 2012, p. 87).

Ahora bien, cabe destacar que las prácticas para conquistar el poder de la universidad por parte de los católicos fueron muy diferentes en comparación con los falangistas. Consideramos que su manera de recristianizar la universidad tuvo principalmente tres ejes: la recuperación del discurso neoescolástico por medio de la creación de la cátedra de Metafísica (ontología y teodicea) de la Facultad de Filosofía y Letras (1951), la aparición habitual de diferentes símbolos religiosos (NO-DO números 987C y 1373B) o bien la visibilidad que se daba de las estudiantes religiosas, identificables por sus hábitos (NO-DO números 1404A) y, por supuesto, la ocupación - a través de las "oposiciones patrióticas" (CLARET, 2006) - de todas aquellas cátedras que todavía se encontraban vacantes a causa de la represión (exilio, prisión, depuración o fusilamiento). De este modo:

numerosas cátedras fueron ocupadas por clérigos, sobre todo de las órdenes religiosas más integristas, como los dominicanos, agustinos y carmelitas, y por miembros de organizaciones católicas, y en menor medida por falangistas, en perjuicio de profesionales prestigiosos que no tenían estas adscripciones. Esto fue especialmente significativo en las facultades de Filosofía y Letras y Derecho, dado el carácter ideológico de buena parte de las materias que impartían. Así, la Acción 
Católica Nacional de Propagandistas (ACNP), que no tenía más que unos 600 socios, logró que sus miembros ganaran el 16 por 100 de las cátedras convocadas en toda España entre 1940 y 1945: sólo en Derecho los propagandistas consiguieron 17 de las 59 convocadas, es decir el 31 por 100 (DE RIQUER, 2010, 326).

Pues bien, el hecho de poner punto y final a la tentación de vertebrar un Estado en un sentido falangista no fue el último cambio del régimen franquista que se puede observar en las pantallas del NO-DO porque, a partir del periodo 1951-1959, se abrió una nueva etapa que pretendía dejar atrás aquella política económica limpiamente autárquica, pero que "permanecía fiel a dos grandes principios: la formación tiene que inspirarse en el concepto cristiano de la vida, en la tradición y cultura patria" (MAYORDOMO, 1997, p. 157), a pesar de que las decisiones de las autoridades fueron cada vez más técnicas que políticas. La cuestión capital es que se aprobó el Plan de Estabilización (1959), que permitió la liberalización de la economía, entrada de capitales extranjeros y normalización de la divisa española. Cabe decir que el nuevo rumbo económico estuvo dirigido por un grupo de técnicos, en la órbita del Opus Dei, que confiaban en valores como eficiencia, productividad, libre empresa o crecimiento económico, que se situó alrededor de un 8,7\%.

Todo ello también tuvo una derivada educativa. Hacía falta, pues, modernizar algunos aspectos de todas las instituciones educativas desde una óptica capitalista, y con este propósito, se aprobó una nueva Ley de Educación (1970) de ascendencia norteamericana. Las principales novedades de este texto legislativo que quería atender los planes de desarrollo fueron las siguientes: ampliación de la escolarización hasta los 14 años de edad, unificación de la enseñanza media, creación de un bachillerato, otorgamiento de una mínima autonomía a la universidad, reestructuración de las carreras universitarias en tres ciclos y creación de unos estudios universitarios para el profesorado. Sin embargo, el cambio más visible a nivel universitario fue la construcción de nuevas facultades, que fueron presentadas de este modo tal y como pone de manifiesto el NO-DO número 827B: 


\begin{abstract}
En la ciudad universitaria de Barcelona se ha construido una nueva Facultad de Derecho. El edificio ocupa dos hectáreas y tiene capacidad para 2.00o alumnos. Ha sido edificado en el tiempo récord de 8 meses. Dispone de tres aulas para 250 alumnos cada una, otras 3 para 150 y 5 para 6o. Además de estos locales, el edifico cuenta con sala de actos, biblioteca y otras dependencias donde los estudiantes pueden disfrutar de esta mejora importante que supone para ellos salir de los exigíos oscuros locales de la universidad literaria para disfrutar de la flamante facultad, de líneas modernas, que rinde así el mejor servicio para el buen desempeño de la tarea estudiantil.
\end{abstract}

Tal y como se puede leer en este fragmento, el nuevo campus universitario construido en la parte alta de la ciudad de Barcelona fue presentado bajo la consigna de la modernización de la enseñanza superior, como ocurrió en otros lugares españoles y, además, fue el tema más recurrente en las apariciones de Franco en el NO-DO (CRUSELLS, 2014, p. 103). Buena prueba de esto son en este caso, sin la presencia del dictador - los NO-DO números 1301B y 1373B, que se hacen eco de las inauguraciones de la Escuela de Bellas Artes San Jorge y de la Facultad de Ciencias Políticas, Económicas y Comerciales respectivamente. Pero tampoco podemos perder de vista que esto respondía a una necesidad social: el crecimiento muy significativo de estudiantes, con la entrada de algunos de ellos provenientes de clases trabajadoras, lo cual hizo cambiar notablemente el paisaje universitario con constantes movilizaciones. De hecho, la situación de aquellos años queda muy resumida en el siguiente fragmento: "yo podría recordar la solemne inauguración, en ese sentido, de edificios, acompañada incluso por el desfile de fuerzas militares, los cuales al día siguiente de la inauguración oficial eran incapaces de contener a los estudiantes matriculados" (PARÍS, 1991, p. 443).

\title{
EXALTACIÓN DE LA JERARQUÍA
}

Dado que la dictadura franquista surgió después de una Guerra Civil iniciada por un levantamiento militar contra un gobierno legítimo, el ejército fue uno de los pilares del régimen, y su influencia política se tradujo en la imposición 
a la sociedad de una serie de valores: autoritarismo, obediencia y respeto a la jerarquía establecida. Posiblemente, este espíritu militar fue uno de los puntos en común más importantes de todos los sectores ideológicos que apoyaban al franquismo y, por este motivo, todo ello se mantuvo como una invariante ideológica durante toda la trayectoria del régimen (ESCOLANO BENITO, 2002). Buena prueba de ello fue el servicio militar obligatorio, porque se convirtió en una herramienta muy importante de adoctrinamiento para todos los jóvenes de aquella época.

Ahora bien, la universidad, del mismo modo que ocurría en el resto de instituciones que formaban parte de la sociedad española de aquellos años, también estaba organizada con los mismos criterios jerárquico-autoritarios, tanto a nivel administrativo como docente. Había, pues, una serie de rutinas: los estudiantes se levantaban cuando entraba el profesor en el aula; solo se aceptaban preguntas al final de la clase y, si estaban mal formuladas, el profesor podía ser muy desagradable, y era el bedel quien avisaba de que era la hora de acabar la sesión. La idea era, por lo tanto, construir un ambiente parecido al cuartel militar, es decir, "de predominio de los valores nacional-católicos, de afirmación fascista, de suplantación de la discusión científica y la apertura al exterior por un concepto jerárquico autoritario en todos los planos y la autarquía intelectual" (GRACIA; RUIZ, 2001, p. 156). Además, no debemos olvidar que había que cumplir, durante este recorrido académico, con las milicias universitarias, que consistían en dos campamentos de tres meses en dos veranos consecutivos y, posteriormente, un servicio de seis meses tras la obtención del título universitario. Sin embargo, antes se tenían que aprobar los dos primeros cursos de los estudios universitarios y pasar las correspondientes pruebas médicas, físicas y psíquicas. Se confirma, por lo tanto, que el joven universitario tenía que ser mitad estudiante y, como el resto de la población, también mitad soldado.

Conociendo todas las ideas expuestas hasta ahora, no nos puede extrañar que la universidad se convirtiera en un escenario donde los uniformes militares y eclesiásticos también tenían cabida. Formaban parte de su liturgia académica a 
causa de su talante ochocentista. Es cuando se hace más evidente la autarquía cultural del régimen. El NO-DO número 511A lo explica de este modo, lo que nos sirve para descubrir quién solía formar parte de la comitiva de autoridades:

\begin{abstract}
En el paraninfo de la Universidad de Barcelona, se efectúa solemnemente la apertura oficial de curso y entrega de diplomas presidida por el ministro de Educación nacional con el rector magnífico, el gobernador civil, el alcalde, el obispo doctor Modrego, el gobernador militar y el presidente de la Diputación. El señor Ruiz Jiménez trató, en su discurso, los importantes problemas relacionados con la escolaridad y el interés que el estado siente por ellos.
\end{abstract}

A pesar de que es evidente que el autoritarismo se convirtió en una invariante ideológica durante todo el régimen, tal como hemos mencionado líneas más arriba, debe destacarse que el NO-DO también fue modulando su discurso como se puede percibir en este instrumento de propaganda. No hay duda de que las diferentes etapas del franquismo que antes hemos mencionado en relación con la lucha por el poder de la universidad y, por extensión, del mencionado medio de comunicación a causa de los cambios que se iban produciendo a escala internacional también se hicieron sentir en este aspecto. Con acierto, el historiador Borja de Riquer (2010) emplea el término "camaleónico" porque, sin abandonar el autoritarismo feroz, el franquismo supo ejercer de forma sucesiva el fascismo, el nacional-catolicismo y, por último, una tecnocracia moderna.

En cualquier caso, la cuestión es que, si en los primeros años el autoritarismo era mucho más explícito en las pantallas de cine, después quedó más bien difuso con otras noticias de una apariencia menos beligerante políticamente, a pesar de que el general Franco siempre defendió que los militares tenían que participar activamente en la vida política (DE RIQUER, 2010). Buena prueba de esto es el Cuadro 2, que a continuación se adjunta, porque queda confirmada la presencia de los ministros en las noticias sobre la Universidad de Barcelona: 
Cuadro 2- Presencia de los ministros de Educación en el NO-DO.

\begin{tabular}{|l|l|}
\hline \multicolumn{1}{|c|}{ MINISTRO } & \multicolumn{1}{c|}{ NÚMERO DE NO-DO } \\
\hline José Ibáñez Martín (1939-1951) & 231A, 302A \\
\hline Joaquín Ruiz-Giménez y Cortés (1951-1956) & 511A \\
\hline Jesús Rubio García-Mina (1956-1962) & 703B \\
\hline Manuel Lora-Tamayo Martín (1962-1968) & - \\
\hline José Luís Villar Palasí (1968-1973) & 987C, 1040C \\
\hline Julio Rodríguez Martínez (1973-1974) & - \\
\hline Cruz Martínez Esteruelas (1974-1975) & - \\
\hline
\end{tabular}

Fuente: Elaboración propia.

Mención especial merecen las tres visitas realizadas por el dictador a las dependencias universitarias en los años 1947, 1948 y 1957, porque "la figura de Francisco Franco es el arquetipo audiovisual mejor construido por el noticiario" (RODRÍGUEZ, 2008, p. 33). Se convirtió en el protagonista indiscutible de la vida de todos los españoles gracias a la tarea realizada por el NO-DO - aparece en un 31,9\% de todas las noticias, según el profesor Magí Crusells (2014) - y, por este motivo, su mera presencia en la noticia tomaba mucha más relevancia que los eventos que se publicitaban. Esto se puede percibir, en el NO-DO número 231A, cuando el locutor dice:

en la Universidad de Barcelona, Franco recibe el homenaje del Profesorado y de los estudiantes. Los claustros y las escalinatas, los salones y el Paraninfo sirven de escenario para este acto de cariño y de adhesión tributado hacia quien, con su acertada política, supo regenerar la Universidad española, dotándola de las más ambiciosas miras y señalándole los más altos destinos. 5

5 Aprovechamos para agradecer, desde estas líneas, la colaboración del señor Luis Antonio Castrillo Aguilera (Filmoteca Española) que nos ha facilitado la transcripción de este registro 
Y, del mismo modo, en la noticia del NO-DO número 774A, que da cuenta del recorrido que Franco hizo en su visita a la Universidad Laboral de Tarragona, porque dicho trayecto concentra más atención que las características de la obra en cuestión, aunque fue una institución educativa muy relevante para el régimen.

En este sentido, vale la pena añadir que la presencia de esta Universidad Laboral es muy significativa porque nos permite destacar la existencia de otro modelo universitario durante el periodo franquista. Dependía, en este caso, del Ministerio de Trabajo (GIRÓN DE VELASCO, 1994) y, por ende, de una retórica nacionalsindicalista, expresión española del nacionalsocialismo tal y como ya se ha comentado anteriormente, porque ya no presentaba dicha institución con la misión de formar élites. Así, pues, sus estudios de orientación totalmente profesional estaban pensados más bien para convertir a los hijos de los obreros en trabajadores graduados (jefes de taller, mecánicos, delineantes, encargados), es decir, entre los arquitectos o ingenieros que continuaban formándose en las universidades del Ministerio de Educación siguiendo el modelo napoleónico y los obreros no calificados. Tampoco podemos olvidarnos que la creación de estos centros garantía el control ideológico de un sector de población proclive a manifestar su malestar públicamente y, especialmente, a las tesis comunistas.

En cualquier caso, es evidente que el mérito del NO-DO fue crear, tal y como sostiene la profesora Araceli Rodríguez (2008), una imagen política de Franco a pesar de sus carencias a la hora de relacionarse con la cámara de forma natural. Nunca fue un gran orador, lo que queda confirmado por el dato que en un $78 \%$ de las noticias es el propio locutor quien cita las ideas clave de su discurso (CRUSELLS, 2014, p. 117), y por este motivo, se puede afirmar que "el mundo en el que Franco ejercía su arbitraje no era, por tanto, el de las asambleas o reuniones de muchos participantes sino el de la conversación privada o la reunión reducida” (TUSELL, 1988, p. 157). En fin, nada que ver con los grandes líderes del momento (Hitler, Mussolini, Eisenhower), lo cual confirma que la combinación de

dado que la versión que se puede consultar en la página web del Archivo histórico del NO-DO no tiene audio. 
imágenes determinadas (el contrapicado era habitual para disimular su estatura) con la música y la voz en off llevaron a cabo un excelente trabajo para construir una única interpretación, clara y sólida, que dejaba poco espacio a la imaginación del público.

Desde esta perspectiva, recuperamos nuevamente la noticia aparecida en el NO-DO número 231A porque podemos ver cómo las imágenes pretenden transmitir que la comunidad académica aprecia al General y, por ello, se destaca especialmente el momento de entrar y salir del Paraninfo de la Universidad porque es cuando se puede ver el entusiasmo de los estudiantes. Las multitudinarias manifestaciones siempre estuvieron muy presentes las dieciséis veces que Franco visitó Cataluña, como también lo fueron discursos como el que hizo el rector de la Universidad de Barcelona en aquellos momentos (Enrique Luño Peña):

la universidad española, y en su nombre y en su representación, la Universidad de Barcelona, se enorgullece de reconocer públicamente el gran interés y la preocupación constante de $\mathrm{Su}$ excelencia y de $\mathrm{Su}$ gobierno por el resurgimiento y esplendor de la cultura, de la investigación y de la enseñanza (GRACIA; FULLOLA: 2008, p. 138).

Asimismo, podemos ver como Franco, en el NO-DO número 338B, da un discurso a la multitud concentrada en la Universidad industrial de Barcelona. Se pueden observar dos detalles que son relevantes a nivel comunicativo: el dictador va vestido de militar, lo que nos recuerda que ganó la guerra, así como la importancia de los valores castrenses, y al mismo tiempo, no se oye su voz directamente. La voz en off es quien nos resume lo que ha dicho. Esto era lo más habitual por razones técnicas, pero el dictador se vio beneficiado por ello porque su voz aflautada no ayudaba a la construcción de su imagen política y mitificación oficial. 


\section{VIDA ACADÉMICA}

En este apartado, hemos reunido todos aquellos registros directamente relacionados con las principales tareas que debe llevar a cabo una universidad, es decir, la docencia y la investigación. Llama la atención que la mayoría de las noticias no se centren en esta cuestión, una ausencia que nos lleva a pensar que al régimen no le preocupaban demasiado las cuestiones puramente pedagógicas. Es todavía más sorprendente que no haya ninguna noticia que aborde directamente algunos de los estudios que se estaban impartiendo en las facultades, ni siquiera todos aquellos que surgieron en pleno franquismo (Económicas, Pedagogía, Biología), ni que se haga referencia al Plan Maluquer, que fue una novedad valorada muy positivamente por la mayoría de profesores y estudiantes, como así se refleja en el siguiente fragmento:

Nadie se licenciaba en nada muy concreto o parcial, sino que hacíamos todos una carrera muy generalista, con enseñanzas obligadas de historia, geografía, filología, filosofía, lenguas clásicas y lenguas modernas. Esto fue la consecuencia del mejor plan de estudios que nunca se haya visto en mi universidad en todo el siglo xx, el llamado Plan Maluquer - hombre que fue decano de la facultad de Letras entre 1969 y 1974 -, que consistía en un mapa muy amplio de asignaturas, entre ellas las de nivel A, que eran obligatorias y generales; las de nivel $\mathrm{B}$, que eran más especializadas y eran elegidas en función de la deseada o concreta formación de cada estudiante, y las de nivel C, habitualmente con una docena de estudiantes, que estaban configuradas como los seminarios de las buenas universidades europeas, con obligada y fácil participación en clase de los estudiantes (LLOVET, 2011, p. 24-25).

Ahora bien, las autoridades del régimen sí que mostraron interés por una práctica docente durante el periodo veraniego que se llevó a cabo en las ruinas de Empúries por parte de estudiantes de Arqueología (NO-DO número 1126A). Merece especial atención el adjetivo "original" que aparece en el encabezamiento de la noticia, porque tras esta opinión, que en absoluto se da de más, se esconde la historia real de esta enseñanza y el nombre del profesor más destacado que se exilió en México a causa de su compromiso republicano: Pere Bosch i Gimpera 
(1891-1974). Es de sobras conocido que el rector de la Universidad Autónoma de Barcelona fue el creador, entre otras empresas relacionadas con la prehistoria, del Servicio de Investigaciones Arqueológicas del Institut d'Estudis Catalans, que permitió realizar una serie de excavaciones en todo el territorio. Y precisamente de la de Empúries fue el director. Pero tampoco se menciona a uno de sus discípulos, que no se exilió y fue quien ocupó la cátedra que había dejado vacante su maestro: Lluís Pericot (1899-1978). Ni al falangista Martín Almagro, que fue quien realmente pasó a controlar la investigación arqueológica.

Algo parecido ocurre con el barco-universidad Seven Seas (NO-DO número $1089 \mathrm{C}$ ) porque, sin recordar los míticos cruceros universitarios por el Mediterráneo (1933), América (1934) y Oriente (1935), puede llevar a pensar al receptor de estas noticias que esta práctica de enseñanza representa una novedad del sistema educativo de los Estados Unidos. No hay duda de que el hecho de poner de relieve una práctica de enseñanza activa con la consigna "aprender viajando" genera una contradicción con todo el sistema educativo franquista, que era totalmente tradicional y sin ningún tipo de síntoma de modernización.

Vistas así las cosas, puede decirse que el NO-DO nos muestra una universidad que permanece lejos de su idea originaria: los estudiantes se divierten en diferentes celebraciones (fiesta de Santo Tomás, pasacalles, teatro, tunas universitarias, el juicio bufo y otros), y los profesores casi no concentran ningún protagonismo. La cuestión es que se puede observar a muchos catedráticos, pero aparecen como si se tratara realmente de un decorado académico más. En realidad, los momentos en que se mencionan sus nombres, a pesar de las palabras grandilocuentes que se les solía dedicar en los discursos por parte de las autoridades del régimen: "ambicionamos profesores universitarios que sean verdaderos maestros, por lo que estableceremos sistemas rígidos y automáticos para su formación y selección en el orden científico y en el pedagógico" (IBÁÑEZ MARTíN, 1944, p. 20). Esta omisión puede ser comprendida, también, por la concepción de cultura que tenía el falangismo. Estamos hablando de una idea muy elitista, pero al mismo tiempo, totalmente 
populista porque, tal y como sucedía en los fascismos europeos, se pretendía construir un ambiente antiintelectual, como si fuera el Palacio del Pardo, donde residía el dictador. Era, pues, el momento de "los partidarios de la acción frente a la inoperancia de la 'palabrería' parlamentaria y liberal" (GRACIA; RUIZ, 2001, p. 160).

Pasemos ahora a la tarea de la universidad en materia de investigación, una faceta que se recoge a través de la celebración de cuatro congresos internacionales: Filosofía, Pediatría, Psiquiatría y Bioquímica. A pesar de que el relato del NO-DO es totalmente triunfalista, con expresiones como "La Universidad de Barcelona es el escenario elegido para el IV Congreso Internacional de Psicoterapia, que congrega a las más importantes personalidades mundiales de este campo científico" (NO-DO número 818B), es evidente que las tres primeras disciplinas experimentaron un descalabro muy significativo en $1939^{6}$. No podemos decir lo mismo de Bioquímica porque surgió más tarde, pero su presencia en el NO-DO sí merece dos comentarios: su relato comunicativo aprovecha para hacer propaganda de las virtudes de la nueva Ley de Educación (1970) porque, según el aparato oficial, ofrece "prometedores horizontes a la juventud investigadora" (NO-DO número 1486A), y que son entrevistados, por primera y única vez, dos científicos de primer orden: Severo Ochoa y Juan Oro. Se aprovecha la ocasión para comunicar un éxito de la ciencia española con el trasfondo de los Estados Unidos como horizonte de todo ello.

También llama la atención que el NO-DO que aborda el Congreso

\footnotetext{
${ }^{6}$ A modo de ejemplo, destacamos la situación paupérrima de la Facultad de Medicina porque, según Corbella (1996), solo se pudieron llenar 4 cátedras de las 12 existentes y, por lo cual, la psiquiatría se suprimió como asignatura a pesar de todo el trabajo hecho por parte de Emili Mira (1896-1964), que fue un profesor de reconocido prestigio. Hasta que se restableció la cátedra, que no fue hasta 1950 a través del profesor Ramon Sarró (1900-1993), estos estudios quedaron cubiertos por la buena voluntad de los profesores Joan Giné y Artur Galceran y, más adelante, por la asignatura Medicina Legal, impartida por el catedrático Manuel Saforcada. La historia de Pediatría es bastante parecida, pero con la diferencia de que la cátedra se pudo recuperar antes, es decir, en 1941, a través del profesor Rafael Ramos Fernández (1907-1955) que, según Corbella (1996), "fue un hombre brillante, activo y eficaz. Un motor de nuestra pediatría". No podemos olvidarnos de Gregori Vidal i Jordana (1894-1980), que fue encarcelado después de la guerra y, por ello, perdió antes la cátedra.
} 
Nacional de Pediatría plantea una visión más asistencialista que científica. Buena prueba de esto es que la principal protagonista de la noticia es directamente la Sección Femenina y su tarea contra la mortalidad infantil (campaña a favor de la vacunación). Este cariz tan ideológico también provoca la ausencia en el reportaje de una institución muy importante en el campo de la medicina infantil: el Hospital de los Niños Pobres, fundado en 1890 por Francisco Vidal Soares. Sin embargo, sucede algo muy distinto en la noticia en la que se presenta el Instituto de Investigaciones Pesqueras (NO-DO número 1173C), en la que se destaca una entidad que el narrador menciona al final de su locución: el CSIC, que pretendía renacionalizar la ciencia española.

Llegados a este punto, merece la pena abordar cuál fue la política científica del régimen franquista, que ya podemos avanzar que se encuentra mayoritariamente fuera de la universidad, tal y como acabamos de comentar. La cuestión es que, antes de la llegada del CSIC con la dirección de José María Albareda y el apoyo del Opus Dei, se plantearon hasta dos proyectos. El primero de ellos fue el Instituto de España, durante el ministerio de Pedro Sainz Rodríguez junto con Julio Palacios Martínez. Era como un gran senado de la cultura, es decir, "se inspiraba en el centenario Institute de France, pero también, en lo referente al control de instituciones científicas preexistentes, en la nueva Academia d'Italia, en la que Mussolini encuadró a la centenaria y venerable Academia dei Lincei" (CANALES, 2009, p. 114). La otra opción vino a propuesta del ministro Lora Tamayo, que quería trasladar el CNR italiano al Estado español. Se quería priorizar, según el profesor Canales (2009), la investigación aplicada al servicio de la autarquía.

Existe un detalle significativo que demuestra la relevancia política del CSIC. El instituto de investigación biológica que antes ha sido mencionado es anterior a la propia facultad de la Universidad de Barcelona (1973). Se generó una relación de dependencia entre las universidades y el CSIC en materia de investigación que resultó fundamental para conquistar la universidad desde posiciones eclesiásticas. No obstante, también es cierto que ya se habían 
elaborado diferentes planes de estudios en la facultad de ciencias (1953 y 1967). En cualquier caso, estamos ante un centro de investigación que presenta:

una triple vertiente, todas relacionadas entre sí: a) como organismo aglutinador y centralizador de toda la investigación científica que se desarrollaba entonces en el país; b) como entidad rupturista con la política científica y la investigación practicada en el primer tercio del siglo XX; y c) como agente recuperador de 'la verdadera tradición científica española', que se remonta sobre todo al siglo XVI (SANTANA, 2009, p. 166).

\section{REFLEXIONES FINALES}

Llegados a este punto final, conviene destacar que el NO-DO como instrumento de propaganda es un reflejo de la trayectoria del régimen franquista, que siempre procuró el mejor escenario para sobrevivir según la coyuntura política de cada momento. El NO-DO estuvo organizado, tal como sucedió con la universidad $\mathrm{u}$ otros organismos, al servicio de un régimen nacionalista $\mathrm{y}$ totalitario. Se pretendía implantar una determinada cultura política a partir de la prensa, de la radio y, por supuesto, del cine, que era muy popular durante aquellos años. Aun así, hay que dejar constancia de que la propia evolución de la política española (tensiones constantes entre las diferentes familias del régimen) e internacional (Segunda Guerra Mundial, democratización de Europa, progreso social y económico) fue modificando su editorial, como se ha podido observar en el tratamiento de las noticias analizadas y su correspondiente representación de la Universidad de Barcelona.

A pesar de esto, dejamos constancia de que este trabajo evidencia que el NO-DO es una fuente de información de primer orden para estudiar, desde la verdad oficial, el franquismo, que continúa siendo, tal como defiende Borja de Riquer (2010), totalmente historiable, e incluso podríamos añadir que es un ejercicio necesario teniendo en cuenta el contexto internacional, que presenta una preocupante deriva autoritaria, con sus implicaciones educativas. Así pues, 
especificamos que este medio presenta un testimonio clave de los diferentes acontecimientos que ocurrieron durante el franquismo con una serie de particularidades que nunca podemos olvidar, es decir, la voluntad de hacer propaganda, la superficialidad, el exceso de anécdotas innecesarias, la carencia de contexto, la despreocupación por la verdad y, por supuesto, los silencios informativos, tan clamorosos en el capítulo de la represión y las disonancias con el régimen. En fin, el NO-DO puede ser interpretado como un oxímoron: no era un noticiero ni un documental, algo que ya fue reconocido por sus propios responsables, porque situaron este noticiario en el terreno del entretenimiento (un tipo de revista de variedades), pero también lo vieron así las propias autoridades, que buscaban, con su control, transmitir un mensaje concreto a propósito de algunas de las cosas que estaban sucediendo en el Estado español. Aquí radica, en parte, su sentido como instrumento de educación popular, porque tenía más que ver con el imaginario que con la realidad, dado que sus contenidos buscaban tanto poner en imágenes la España anhelada por la jerarquía franquista como la imagen del Estado español que se quería vender oficialmente.

Todo ello es bien plausible en todas las imágenes relacionadas con la Universidad de Barcelona que han sido analizadas en este artículo a partir de los tres ejes narrativos establecidos. De ahí que este centro académico y otros de la misma naturaleza quedan representados como un espacio "pseudorreal", porque lo más importante no era lo que sucedía realmente en su interior que era una enseñanza elitista y de espíritu tradicionalista ("contrarrevolución pedagógica"), sino transmitir lo que necesitaba políticamente el régimen; es decir, situaciones de normalidad, jerarquía, éxito y, por supuesto, de encuadre a la audiencia del NO-DO. Algo que todavía cobró más importancia en la Universidad de Barcelona, porque no podemos olvidarnos que era bien conocida su implicación política durante los tiempos republicanos y, por ello, es tan relevante que la primera noticia del NO-DO informe de la visita de Franco a la universidad catalana.

De esta manera, se puede afirmar que el NO-DO muestra, a través de las palabras y las imágenes, una universidad vaciada de su contenido académico 
salvo contadas excepciones. La docencia y la investigación permanecen en un segundo plano a nivel informativo. No cabe duda que la poca presencia de la figura del profesor y la desvirtuación del estudiante como un sujeto más bien preocupado por la diversión en las noticias analizadas nos confirma que los intereses de la dictadura en materia universitaria eran básicamente otros. En este sentido, se confirma la tesis de Pedro Laín Entralgo (1976) cuando pone de manifiesto qué esperaban las autoridades franquistas de las universidades: "el anual suministro de títulos profesionales y la carencia de disturbios estudiantiles en las aulas o en la calle" (LAIN ENTRALGO, 1976, p. 385).

En fin, concluimos dejando constancia que el NO-DO cumplió su misión comunicativa porque contribuyó a enmascarar la regresión de la Universidad de Barcelona y, por supuesto, de todo el sistema de educación superior español durante el régimen de Franco (HERNÁNDEZ, 1997; FULLOLA, 2007; VIÑAO, 2014) transmitiendo, con fines propagandísticos, un relato comunicativo para toda la población que defendía que dicha institución funcionaba sin apenas dificultades ni limitaciones. Sus ideas y argumentos, nunca neutros ni objetivos, bascularon de la situación de los primeros años del régimen, caracterizada por el compromiso público de las autoridades del régimen y la excelente acogida que recibieron por parte de toda la comunidad académica en un ambiente nacionalsindicalista, hasta la idea del desarrollo y de la modernización, con la inauguración de diferentes facultades al final de la dictadura. Aun así, y a pesar de dichos cambios en las políticas de ordenación universitaria, la utilización del NO-DO como canal de información para difundir la lealtad a los valores del Movimiento nacional persistió hasta el final del régimen.

\section{REFERENCIAS}

AGUILAR, Raul. Universitat de Barcelona. In: Centre d'Estudis sobre Èpoques Franquista i Democràtica (CEFIS). Catalunya durant el franquisme.

Diccionari. Vic: Eumo Editorial, 2006. p. 399-400. 
Archivo histórico del NO-DO. Radiotelevisión Española y Filmoteca española. Disponible en: http://www.rtve.es/filmoteca/ Acceso en: nov. 2019.

BURKE, Peter. Historia social del conocimiento. v. II. Barcelona: Paidós, 2012.

CANALES, Antonio Francisco. La política científica de posguerra. In: GÓMEZ, Amparo; CANALES, Antonio Francisco (ed.). Ciencia y fascismo. La ciencia española de Posguerra. Barcelona: Laertes, 2009. p. 105-136.

CASASSAS, Jordi; GRACIA, Francisco; FULLOLA, Josep Maria (coord.). La Universitat de Barcelona: libertas perfundet omnia luce, 1450. Barcelona: Publicacions i Edicions de la Universitat de Barcelona, 2008.

CLARET, Jaume. El atroz desmoche. La destrucción de la universidad española por el franquismo, 1936-1945. Prólogo de Josep Fontana. Barcelona: Crítica, 2006.

CLARET, Jaume. La repressió franquista a la universitat catalana. La Universitat de Barcelona autònoma, de la Segona República al primer franquisme. Barcelona: Institut Universitari d'Història Jaume Vicens i Vives / Eumo Editorial, 2003.

CLARET, Jaume. Perturbaciones del orden académico. Els estudiants de la universitat catalana entre el blau i el vermell (1939-1975). Recerques, n. 73, p. 133-159, 2017.

COLLELLDEMONT, Eulàlia (coord.). Registro de los reportajes y noticias en los que aparece representada la Educación (1940-1975). Vic: Universitat de Vic-Universitat Central de Catalunya, 2018. Disponible en: https://www.uvic.cat/museu-virtual/investigacions/araef Acceso en: abril 2020.

\section{CORBELLA, Jacint. Història de la Facultat de Medicina de Barcelona} 1843-1985. Barcelona: Fundació Uriach 1838, 1996.

CRUSELLS, Magí. Franco, ¿̇protagonista del NO-DO?. In: CAPARRÓS, Josep Maroa; CRUSELLS, Magí; SÁNCHEZ, Francesc (ed.). Memoria histórica y cine documental. Barcelona: Edicions de la Universitat de Barcelona, 2014. p. 91-117.

DE RIQUER, Borja. La dictadura de Franco. v. 9. Barcelona: Crítica, Marcial Pons, 2010.

DISPONIENDO la proyección obligatoria y exclusiva del Noticiario 
Cinematográfico Español y concediendo la exclusividad absoluta de reportajes cinematográficos a la entidad editora del mismo, Noticiarios y Documentales, Cinematográficos "NO-DO". Boletín Oficial del Estado, n. 356, p. 10.444, 22 de diciembre de 1942.

DUSSEL, Inés. La verdad en la imagen propagandística. Reflexiones sobre un corpus enigmático (Westerbork, 1944). Historia y memoria de la educación, n. 8, p. 23-58, 2018.

ESCOLANO BENITO, Agustín. La educación en la España

contemporánea. Políticas educativas, escolarización y culturas pedagógicas. Madrid: Biblioteca Nueva, 2002.

GIRÓN DE VELASCO, José Antonio. Si la memoria no me falla. Barcelona: Planeta, 1994.

GÓMEZ, Anna. Fonaments metodològics d'investigar amb les imatges.

Referències des de la investigación. In: COLLELLDEMONT, Eulàlia (coord.). Investigar la història de l'educació amb imatges. Vic: Eumogràfic MUVIP, 2014. p. 77-100.

GRACIA, Jordi. Estado y cultura. El despertar de una conciencia crítica bajo el franquismo (1940-1962). Prologo de José Carlos Mainer. Toulouse: Presses Universitaires du Mirail, 1996.

GRACIA, Francisco; FULLOLA, Josep Maria. La nit! In: CASASSAS, Jordi; GRACIA, Francisco; FULLOLA, Josep Maria (coord.). La Universitat de Barcelona: libertas perfundet omnia luce, 1450. Barcelona: Publicacions i Edicions de la Universitat de Barcelona, 2008. p. 102-147.

GRACIA, Jordi; RUIZ CARNICER, Miguel Ángel. La España de Franco (1939-1975). Cultura y vida cotidiana. Madrid: Editorial Síntesis, 2001.

HERNÁNDEZ, José María. La universidad en España, del antiguo Régimen a la LRU (1983). Hitos y cuestiones destacadas. Aula, n. 9, p. 19-44, 1997.

IBÁÑEZ MARTÍN, José. Realidades universitarias en 1944. Discurso pronunciado por José Ibáñez Martín en la solemne inauguración del curso académico 1944-45 en la Universidad de Valencia. València, 1944.

LAIN ENTRALGO, Pedro. Descargo de conciencia (1930-1960). Barcelona: Barral editores, 1976.

LAUDO, Xavier; VILANOU, Conrad. Educational discourse in Spain during the early Franco regime (1936-1943): toward a genealogy of doctrine and concepts. 
Paedagogica Historica. International journal of the history of education, v. 51, n. 4 extra, p. 434-454, 2015.

LLOVET, Jordi. Adiós a la Universidad. El eclipse de las humanidades. Barcelona: Galàxia Gutenberg, 2011.

LÓPEZ BAUSELA, José Ramón La contrarrevolución pedagógica en el franquismo de guerra. El proyecto político de Pedro Sainz Rodríguez. Madrid: Biblioteca Nueva / PUbliCan - Ediciones de la Universidad de Cantabria, 2011.

MAYORDOMO, Alejandro. Nacional-catolicismo, tenocracia y educación en la España del franquismo (1939-1975). In: ESCOLANO BENITO, Agustín; FERNANDES, Rogério (ed.). Los caminos hacia la modernidad educativa en España y Portugal (18oo-1975). Salamanca: Sociedad Española de Historia de la Educación, 1997. p. 147-174.

MORENO, Amparo; ROVETTO, Florencia; BUITRAGO, Alfonso. ¿De quién hablan las noticias? Guía para humanizar la información. Barcelona: Icaria, 2007.

PARÍS, Carlos. La pretensión de una universidad tecnocrática (Panorama de la universidad española desde 1956 hasta 1975). In: CARRERAS ARES, Juan José; RUIZ CARNICER, Miguel Ángel (ed.). La universidad española bajo el régimen de Franco (1939-1975). Zaragoza: Institución Fernando el Católico, 1991. p. 437-454.

PAYNE, Stanley G. En defensa de España. Desmontando mitos y leyendas negras. Barcelona: Espasa, 2019.

POBLET, Àngel; DURAN, Lluís. L'esclat de la cultura. Català a l'escola i arreu. In: AAVV. El franquisme a Catalunya (1939-1977) 3. La immigració, el desarrollismo i la resistència cultural (1959-1968). Barcelona: Edicions 62, 2006. p. 194-213.

RODRÍGUEZ MATEOS, Araceli. Un franquismo de cine. La imagen política del Régimen en el noticiario NO-DO (1943-1959). Madrid: Ediciones Rialp, 2008.

RUIZ-GIMÉNEZ, Joaquín. Diarios de una vida (1967-1978). Madrid: Cortes Generales Defensor del Pueblo, 2013.

SANTANA, Margarita. Unidad de la patria, unidad de la ciencia: la retórica científica del régimen franquista. In: GÓMEZ, Amparo; CANALES, Antonio 
Francisco (ed.). Ciencia y fascismo. La ciencia española de Posguerra. Barcelona: Laertes, 2009. p. 165-184.

SANTACANA, Carles. "iMuera la inteligencia!" Política educativa i cultural. In: SEGURA, Antoni; MAYAYO, Andreu; ABELLÓ, Teresa (dir.). La dictadura franquista. La institucionalització d'un règim. Barcelona: Edicions Universitat de Barcelona, 2012. p. 87-112.

TRANCHE, Rafael; SÁNCHEZ-BIOSCA, Vicente. NO-DO. El tiempo y la memoria. Madrid: Filmoteca española, 2000.

TUSELL, Javier. La dictadura de Franco. Madrid: Alianza, 1988.

VIÑAO, Antonio. La educación en el franquismo (1936-1975). Educar em Revista, n. 51, p. 19-35, 2014.

ZUBIAUR CARREÑO, Francisco Javier. El cine como fuente de la historia. Memoria y Civilización (M\&C), n. 8, p. 205-219, 2005.

JORDI GARCIA FARRERO es pedagogo, Magíster en Historia contemporánea y mundo actual, PhD por la Universitat de Barcelona. Profesor del Departamento de Teoría e Historia de la Educación de la Universitat de Barcelona. Investigador asociado del Grupo de investigación en Pensamiento Pedagógico y social (GREPPS). Sus líneas de investigación son el estudio de los discursos pedagógicos contemporáneos y la historia de la idea de la universidad.

E-mail: jgarciaf@ub.edu

(b) http://orcid.org/0000-0002-9669-0485

ANNA GÓMEZ-MUNDÓ es doctora en Pedagogía. Profesora del Departamento de Pedagogía de la Universitat de Vic - Universitat Central de Catalunya. Investigadora del Grupo de investigación en Educación de la Universitat de Vic (GREUV). Sus líneas de investigación son la relación educativa y la narrativa en la educación

E-mail: anna.gomez@uvic.cat

(1) http://orcid.org/0000-0003-1182-3910 
Revista História da Educação (Online), 2020, v. 24: e98710 DOI: http://dx.doi.org/10.1590/2236-3459/98710
e-ISSN: 2236-3459 http://seer.ufrgs.br/asphe

Recebido em: 03 de dezembro de 2019

Aprovado em: 12 de maio de 2020

(c) (

Associação Sul-Rio-Grandense de Pesquisadores em História da Educação - Asphe Artigo de acesso aberto distribuído nos termos de licença Creative Commons. 